\title{
PENGGUNAAN RESIN EPOKSI UNTUK PEGANGAN ALAT-ALAT DAPUR
}

\author{
Oleh : Dwi Wahini Nurhajati, Agustin Suraswati, Pramono \\ Supriyanto B dan Supriyadi
}

\begin{abstract}
Application of epoxy resin to make the kitchen tolls holder was investigated. Optimum compound of kitchen tools holder was reached for compoun which it consist of epoxy resin : 100 parts, hardener 100 parts, carbon black. 50 parts. Applied test in hot water show that the kitchen tools holder from research is better than the kitchen tools holder from markets.

\section{INTISARI}

Telah dilakukan penelitian tentang penggunaan resin epoksi untuk pegangan alat-alat dapur. Formula kompon pegangan alat dapur yang optimum dicapai untuk kompon yang berisi resin epoksi 100 bagian, hardener 100 bagian. dan carbon black 50 bagian. Hasil uji pemakaian dalam air panas menunjukkan bahwa pegangan alat-alat dapur hasil penelitian lebih baik dibandingkan pegangan alat-alat dapur yang ada di pasaran
\end{abstract}

\section{PENDAHULUAN}

Resin epoksi termasuk jenis plastik termoset yang mempunyai sifat anti karat, kuat, tingkat penyusutannya kecil, daya rekatnya baik dan tahan terhadap kondisi lingkungan. Resin epoksi yang paling umum adalah resin yang dibuat dari bisphenol $\mathrm{A}$ dengan epichlorohydrin. Pada umumnya resin-resin epoksi yang komersial berupa hasil polimerisasi parsiil yang berbentuk cairan kental atau padatan. Resin epoksı yang berbentuk cairan kental umumnya digunakan untuk proses tuang, laminasi, perckatan dan pelepisan Sebagai plasti termoset, resin epksi ini di "curing" dengan penambahan " curing agent "atau "hardener" ( 1.2)

Penggunaan resin epoksi dalam proses "molding" umumnya dalam bentuk komposit. Bahan pengisi ( "filler") yang umum digunakan meliputi silika, kalsium karbonat,dan aluminium powder , dan lain-lain. Tujuan dimasukkannya filler ini adalah untuk mengurangi penyusutan dan reaksi eksotermis, menurunkan harga dan untuk memodifikasi sifat-sifat produk hasil "curing".

Alat-alat dapur dari logam yang menggunakan pegangan dari plastik sudah ada di pasaran, namun pegangan tersebut mudah lepas jika kena panas pada waktu digunakan pada kurun waktu yang tidak begitu lama. Hal ini disebabkan plastik yang digunakan tidak mempunyai daya rekat yang baik terhadap logamnya. Oleh karena itu penelitian ini bertujuan untuk mencoba menggunakan resin epoksi sebagai pegangan alat dapur Pada percohaan in digunakan carbon black sebagai bahan pengisı 


\section{MATERI DAN METODE PENELITIAN}

1. Bahan

Bahan-bahan yang digunakan dalam percobaan ini adalah resin epoksi, hardener, carbon black dan alat dapur ( "kitchen tools" ).

\section{Peralatan}

Peralatan yang digunakan adalah timbangan listrik, alat uji kekerasan ( shore D Durometer ), alat uji ketahanan pukul , kompor listrik, dan cetakan pegangan alat dapur dari karet silikon.

3. Proses pembuatan kompon.

Agar supaya resin epoksi dapat dicetak menjadi pegangan alat dapur maka resin epoksi dibuat dulu menjadi kompon dengan mencampur resin tersebut dengan bahan pengisi ( "filler"). Pada percobaan ini resin epoksi dicampur dengan filler carbon black yang jumlahnya bervariasi ( lihat tabel 1), lalu diaduk hingga homogen. Selanjutnya campuran tersebut dicampur dengan "hardener" dan diaduk sampai homogen. Perbandingan resin epoksi dengan hardener adalah $1: 1$

Tabel 1. Formula Kompon Pegangan Alat Dapur

\begin{tabular}{|c|c|c|c|}
\hline Formula & Resin Epoks (bag) & Hardener (bag) & Carbon black (bag) \\
\hline 1 & 100 & 100 & 10 \\
2 & 100 & 100 & 20 \\
3 & 100 & 100 & 30 \\
4 & 100 & 100 & 40 \\
5 & 100 & 100 & 50 \\
\hline
\end{tabular}

4. Proses Pencetakan Pegangan Alat Dapur

Kompon epoksi dengan formula seperti tabel 1 dicetak menjadi pegangan alat-alat dapur menggunakan sistem cetak tuang pada suhu kamar dengan cetakan dari karet silikon. Kompon plastik dituang ke dalam cetakan sedemikian rupa sehingga pada waktu tangkai alat-alat dapur dimasukkan ke dalam cetakan yang berisi kompon, kompon tersebut tidak tumpah. Selanjutnya kompom didiamkan pada suhu kamar sampai ter"curing" sempurna. Untuk resin epoksi dengan perbandingan hardener $=1$ : 1 , waktu "curing"nya adalah 24 jam

\section{Pengujian}

Kompon epoksi dengan formula seperti tabel 1 diuji sifat kekerasan dan ketahanan pukulnya. Formula dengan hasil uji terbaik selanjutnya dicetak menjadi pegangan alat dapur dan diuji pakai dalam air mendidih untuk menentukan usia pakai pegangan

Vol XIV No $26^{\text {Th }}$. $1998 / 1999$ alat dapur yang dibuat dan dibandingkan dengan pegangan alat dapur yang ada dipasaran

\section{HASIL DAN PEMBAHASAN}

Untuk menentukan formula yang paling optimum untuk dibuat sebagai pelapis pegangan alat-alat dapur maka dilakukan uji sifat fisis

Hasil uji sifat fisis kekerasan dan ketahanan pukul untuk kompon epoksi yang akan digunakan sebagai pelapis pegangan alat-alat dapur dapat dilihat pada tabel 2

Tabel 2. Hasil uji kekerasan dan ketahanan pukul kompon epoksi untuk pegangan alat-alat dapur

\begin{tabular}{|c|c|c|}
\hline Formula & Kekerasan, Shore D & Ketahanan Pukul \\
\hline 1 & 57,0 & $5 \times$ ulangan pecah \\
2 & 58,4 & $5 \times$ ulangan pecah \\
3 & 60,4 & $5 \times$ ulangan pecah \\
4 & 62,4 & $10 \times$ ulangan pecah \\
5 & 63,0 & $10 \times$ ulangan pecah \\
Kontrol 1 & 65,0 & $5 \times$ ulangan pecah \\
Kontrol 2 & 65,0 & $5 \times$ ulangan pecah \\
\hline
\end{tabular}

Kontrol 1 terbuat dari Melamin Formaldehid dengan kekerasan 65 shore D, sedangkan kontrol 2 terbuat dari plastik thermoplas yaitu polipropilen dengan kekerasan 65 shore D. Kompon formula I dengan kandungan bahan pengisi carbon black sebanyak 10 bagian dengan kekerasan 57,0 shore D , kompon formula 2 yang berisi carbon black 20 bagian dengan kekerasan 58,4 dan kompon formula 3 yang berisi carbon black 30 bagian dengan kekerasan 60,4 shore $D$, pecah pada waktu diuji ketahanan pukul untuk 5 kali ulangan, sedangkan untuk formula 4 yang berisi carbon black 40 bagian dengan kekerasan 62,4 shore D, dan formula 5 yang berisi j berisi carbon black 50 bagian dengan kekerasan 63,0 shore D, pecah pada waktu diuji ketahanan pukul untuk $10 \mathrm{kali}$ ulangan. Dari tabel 2 terlihat bahwa semakin banyak carbon black yang ditambahkan kompon semakin keras dan lebih tahan terhadap pukulan. Dari tabel 2 terlihat bahwa sifat fisis kompon 4 dan 5 tidak jauh berbeda, sedangkan kalau ditinjau dari segi ekonomi formula 5 dengan kandungan carbon black lebih banyak tentunya lebih ekonomi, oleh karena itu formula 5 dipilih untuk dicetak menjadi pegangan alat dapur dan selanjutnya diuji pakai dalam air mendidih. Hasil uji coba pegangan alat dapur dalam air mendidih dapat dilihat padat tahel 3
Majalah Barang Kulit, Karet dan Plastik 
Tabel 3. Hasil ujı coba pegangan alat dapur dalam air mendidih.

\begin{tabular}{|c|c|c|}
\hline Kode & Waktu & Hasil uj coba \\
\hline 1 & 2 & 3 \\
\hline $\mathrm{HIP}$ & 30 jam & $\begin{array}{l}\text { sedikit kusam } \\
\text { ada sedikit gelembung udara }\end{array}$ \\
\hline HIK & 30) jam & $\begin{array}{l}\text { kusam } \\
\text { hanyak terdapat lubang-lubang udara }\end{array}$ \\
\hline $112 \mathrm{P}$ & 30 jam & $\begin{array}{l}\text { kusam } \\
\text { ada sedikit gelembung udara }\end{array}$ \\
\hline $\mathrm{H} 2 \mathrm{~K}$ & $30 \mathrm{jam}$ & $\begin{array}{l}\text { kusam } \\
\text { retak }\end{array}$ \\
\hline
\end{tabular}

H1P dan H2P merupakan pegangan alat dapur hasil percobaan, sedangkan H1K dan $\mathrm{H} 2 \mathrm{~K}$ adalah pegangan alat dapur yang dibeli dari pasaran. Dari tabel 3 terlihat bahwa waktu penggunaan yang sama yaitu 30 jam ternyata bahwa pegangan alat dapur hasil percobaan yang dibuat dari resin epoksi lebih awet dibanding dengan pegangan alat dapur yang dibeli dipasaran.

\section{KESIMPIIAN}

Kesimpulan yang dapat diambil dari hasil percobaan penggunaan resm epokss untuk pegangan alat dapur adalah

1 Resin epoksı dapat dicetak menjadi pegangan alat dapur menggunakan sistem tuang dengan waktu "curing" 24 jam menggunakan bahan pengisi carbon black

2. Formula kompon yang optimum untuk pegangan alat dapur adalah

$\begin{array}{lr}\text { resin epoksi } & 100 \text { bagian } \\ \text { harder } & 100 \text { bagian } \\ \text { carbon black } & 50 \text { bagian }\end{array}$

3. Hasil uji penggunaan menunjukkan bahwa pegangan alat dapur hasil percohaan lebih awet dibanding dengan pegangan alat dapur yang dibeli di pasaran.

\section{I)AITAR PISTIAKA}

I Brydson, JA . "Plastics Materials". Fourth I dituon. Polytechnics of North I on don, 1982

2 Rachmat Supardi. II. Drs. "Metal Indonessa" Vol 111519093 . hal $36,38(190) 3)$ 